\title{
IMPACT OF SOCIO-ECONOMIC STATUS ON WOMEN'S WELL-BEING
}

\author{
VENKATANARAYANAN \\ INDIAN COUNCIL OF SOCIAL SCIENCE RESEARCH (ICSSR), \\ NEW DELHI \\ VALENTINA FUSARI \\ UNIVERSITY OF PAVIA, ITALY \\ S.VEERAMANI \\ JAmia MiLlia ISLAmia UnIVERSITY, NeW DELHI
}

\begin{abstract}
The existing social cleavages based on class, caste, gender, religion, and ethnicity have differential impact on health. Our paper focuses on how health status reflects gender imbalance both in traditional and complex societies, in developing and developed countries. The correlation between gender and health status is intricate and contentious, thus our aim is to investigate it, highlighting why and where women's social status is low, also their health conditions, compared to the male ones, and how they are threatened by a long series of social and environmental factors. In order to prove such assumption we use different case studies concerning malnutrition, complications with pregnancies and Sexual Transmitted Diseases (STDs), short and long-term consequences of Female Genital Mutilation (FGM), as well as restricted access to modern health care. These issues affect women in different ways depending on their social and economic status, but also on the area where they live (developing/developed; rural/urban; and so on). Furthermore, they allow us to move from local to global in the age of globalisation and mediatisation. Our paper presents a range of data gathered mainly through secondary sources giving evidence of the fact that health risk factors are more gender biased against women.
\end{abstract}




\section{Introduction}

Gender-based inequality and its resultant hierarchical relationship predominantly occupy the history of mankind for several thousand years and is still a prevailing force in the socio-economic realms of human life. This is reflected in every social sphere and phenomenon that humans experience. The instance of deprivation, exploitation and exclusion of women, which drives them to live in conditions of poverty, living a marginalized life, stands as living evidence of the contemporary world. The impact of poverty in all societies is not definitive, as it tries to use the existing social cleavages based on class, caste, gender, religion, and ethnicity to have a differential impact. Women are one of the most vulnerable groups in any society, therefore the relation between gender and poverty needs in-depth analysis to comprehend the impact of poverty in women's lives. The health of, and healthcare for, women are one main area where we can discern the impact of poverty in a more concrete form. In this paper gender refers to the rules, norms, customs, and practices by which biological differences between males and females are translated into socially constructed differences between men and women and boys and girls, which results in the two genders being valued differently, as well as in their having unequal opportunities and life chances.

Men and women are biologically different, but the values and implications based on that difference, which impact upon their lives, are the result of interactions and outcomes in the cultural sphere in every society (Lerner, 1986; 6). The invisibility and opaqueness of gender based discriminations make it different from other forms of discrimination based on race, color, caste or class. Personal relations, in the private sphere of family, act as a veneer, with domination and subjugation underneath it. The exclusion and discrimination of women in the public sphere, historically, was secured citing their so-called "natural disabilities", such as inferior reasoning and enslavement to passions (Vogel, 1986; 17). Thus, historically, many common elements of gender based discrimination are found within the societal structures and its functioning in different socioeconomic formations, such as pre-capitalist, feudal, neo-colonial, capitalist or socialist setups. Such kinds of gender based discrimination and exclusion of women have made them a weaker gender excluding them from all spheres of development including health. Thus, narrow focusing on a specific sphere without comprehending the nature and functioning of gender relations in our society will only show the correlation between women's economic position and their vulnerability, overlooking the origins of women's weaker economic position and economic dependency (Payne, 1991; 31). 
The productivity of a population is directly affected by its health status. The female population absorbs most of the reproductive load in addition to the productive role, which unfortunately is still considered marginal and little recognized worldwide. In itself, the reproductive role raises health risks of the female population, for example through the risks due to unsafe motherhood, maternal mortality, female genital mutilations, and so on. In addition, women's social status can lead to a lack of attention and care towards them, justified by the lower position they have in the society compared to men. This role may also lead to lower pay in the labour market as women usually have subordinate professional roles, are poorly paid and are exposed to occupational hazards that degrade women's health. This situation reinforces a vicious circle from which it is difficult to get out, in the absence of policies aimed at encouraging not only reproductive health, but the health of women per se, so that women can offer even greater impact and socio-economic contribution in their families, communities, and societies.

The particular geopolitical environment shapes and fosters specific determinants of women's health, which includes country-specific history and geography, policies and services, legal rights, organizations and institutions, and structures that lays a framework for perpetuating gender and economic inequality within that particular environment. Culture, norms and sanctions, at the country and community level, and sociodemographic characteristics at the individual level, influence women's productive and reproductive roles in the household and workplace. Social capital, roles, psychosocial stresses and resources, health services, and behaviours mediate social, economic and cultural effects on health outcomes (Moss 2002; 649).

The Convention for the Elimination of All Forms of Discrimination against Women (CEDAW) in 1979 provided a legal framework for the promotion of gender equity in health and reproduction, as well as in social and economic life. Epidemiologists and demographers have started to analyse women's daily lives to understand the factors that shape their health. Development economists, researchers and advocates work on issues, which highlight the socioeconomic inequality as one of the driving engines that ends in women's disadvantage (Schultz, 1997). Therefore, women's health inequality is deeply entrenched in the socio-economic structures, which define and mould their lives. 


\section{Understanding Gender}

The gender based subordination is considered as one of the most important axis of power relations between men and women in social life. In all societies, gender relations play a role in the division of labour, distribution of work, access to income, wealth, health, education, public goods and services, and so on. In most societies, women are likely to work longer hours than men, have lower earnings, education, wealth and less access to health services, credit, information and knowledge. Gender biased resource allocation is often reflected within households as well as within local and national budgets (Cagatay, 2000). Gender biases in social life get transmitted through a variety of institutions, other than family, like markets, schools, health services, religious institutions and so on. In fact, gender relations permeate all aspects of socio-economic life, creating gendered socio-economic structures.

Thus, gender is a basic organizing principle, which shapes activities, roles and opportunities from the macro level of the societal economy, through the institution of society, to interpersonal relations. Gender inequality is persistent across all groups within societies. It is a social constant permeating through all structures leading to a subtle institutionalization. It has emerged as a universal value for all categories organized as class, caste, or race. The forms taken by gender inequality may vary across different strata within the society, but they are always more severe among the poor as compared to the rich. As a result, gender inequality intersects with economic deprivation to produce more intensified forms of poverty for women than men. Therefore, gender is not only used in the study of individuals' attributes, but also to understand the institutions' attitudes as they are also gendered. This inequality is reflected in many aspects of our social life like family, employment, education, and health where women are deprived, excluded and forced to be inferior to men.

The Millennium Development Goals Report (2012) underlines the fact that gender and inequality persist and women continue to face discrimination within family, in access to healthcare, education, employment and economic assets, influencing the risk for them of living in poverty, as poor health, lack of education and environmental resources deprive women of productive employment. These aspects of social life, which reflect the gender based subordination, can be witnessed in all hitherto existing social formations, including the contemporary capitalism, for their benefit and development. Even in richer societies, women, being treated as socially inferior, face discrimination in many forms. In order to 
prove such an attitude toward gender discrimination and how it is perpetrated both at familial and institutional level, the focus of this paper will be on health, as a key factor of women's wellbeing. As Buvinić et al. (2006; 195) stated:

\begin{abstract}
"In health, more than in other social sectors, sex (biological) and gender (behavioural and social) variables are acknowledged as useful parameters for research and action, because biological differences between sexes determine male-specific and female-specific diseases but the behavioural differences between the genders assign a critical role to women in relation to family health".
\end{abstract}

\title{
Gender and Women's Health
}

During the 1960s and 70s, there emerged an interest in women's fertility behaviour to curb population growth and to improve maternal and child welfare, which accidentally steered the way towards other women's health issues. During the 1980s, activists and scholars tried to design a women-centred perspective including awareness of how women's inferior gender status in society affected their health. Thus, in 1994, at the United Nations International Conference on Population and Development in Cairo, women's reproductive health and rights earned a place at the centre of the population and development debate, which was further reinforced by United Nations Women's Conference in Beijing (1995) that underlined the importance of gender perspective in health. After two decades, attention concerning women's health expanded to cover other issues unrelated to reproduction and aimed at identifying gender inequities and their causes in healthcare. In recent years, there is an attempt to move beyond the traditional international health focus on women's diseases related to their reproductive and maternal functions, in order to incorporate gender consideration to increase health equity.

There has been considerable increase in gender and linked inequalities in health over the last two decades. In Africa and the Middle East, the development of a female health movement has been slower than in Europe and North America. Issues of sexuality and contraceptive safety are considered a luxury in the context of poor health infrastructures and rising poverty. NGOs active in the health field address the need for basic healthcare services, especially those preventing maternal mortality and infertility (Silliman 1997: 109). Sex and gender can act alone (i.e. uterine cancer), independently (i.e. domestic violence) or interactively (i.e. depressive disorders or HIV/AIDS infection rates) in determining differentials in health status, but the variable, fluid, complex and contested 
categorizations and relationships constitute the reality of gender health discrimination. Thus, in conceptualizing poverty, vulnerability and marginality, the gender dimension should be included. Gender differences and inequalities can give rise to inequities in health status because the control over resources determines differential exposure to risk and access to benefits of health technology and care.

The gender-based subordination of women permeates and reproduces the patriarchal values in the domain of women's health to sustain its dominance. The gender differential impact and its consequences are reflected in patterns of health and illness around the world (Hartigan, 1999). In societies where women's social status is low, their health conditions, compared to the male ones, are threatened by a long series of social and environmental factors, such as eating last and less, complications with frequent pregnancies and Sexually Transmitted Diseases (STDs), negative consequences of Female Genital Mutilation (FGM), restricted access to modern healthcare. The social status influences how care is allocated within the family as Santow $(1995 ; 154)$ stated:

"A lower-status individual, such as a young female, was likely to be treated only with home remedies; when assistance was sought outside the household it was more likely to be from a traditional than a modern therapist. A higher-status individual, such as a male of almost any age or an adult mother of sons, was likely to be taken directly to a private medical practitioner".

Most of the time a woman cannot receive needed healthcare because norms in her community prevent her from travelling alone to health facilities. As a result, for instance, in India even though women reported more illness than men, hospital records show that men received more treatment. In the time of crisis, women are the ones who cut back on their food consumption for other family members to sustain. Even in normal times, the best quality of food or meat is mostly consumed by the male members of the family (Charles \& Kerr, 1988). The lack of nutrition and resources, with increased pressure of their multiple roles and tasks, along with a hazardous labour environment, makes poor women more susceptible to ill health aggravated by delayed or absent medical help.

\section{Women's Work and Health}

Women's work and employment patterns convey the changing patterns of childbearing, family structure, declining fertility rates, decreasing infant 
and maternal mortality rates (Hilfinger Messias et al. 1997: 296). Furthermore, cultural, socio-economic and political factors affect the context of women's daily work and health. In spite of differences in classes, cultures and societies, women's work is subjected to socioeconomic devaluation worldwide. In fact, in contrast to the "masculine" definition of work as employment, women's work is often assimilated to the "feminine" reproductive work of pregnancy and childbirth, as they are universally recognized as women's work. Although this perception is widely diffused, women are engaged in many types of work activities throughout their life span, in addition to their biological and social reproductive work. According to WHO, (2009; 3):

"Gender-based inequalities - as in education, income and employment limit the ability of women to protect their health and achieve optimal health status".

Education, socialization and upbringing throughout the world reeks of gender biased attitudes, which direct the way workers manage their illnesses, their perception of risk, and the propensity to take sick leave or to seek treatment. Thus, biological, psychological and social differences in the context of risk exposure produce sex-specific patterns of occupational health problems.

Gender role based traditional occupations are an impending source of health hazards as work itself is a social determinant of health as demonstrated by occupational epidemiology and work related inequalities in health. This kind of inequality intersects with other axes of inequalities at the individual level (i.e. social class/caste) and at the contextual level (i.e. Neoliberal Political Economy). In sociocultural contexts where fertility determines the social status of women, they experience difficulties related to maternal health. In fact, high fertility rates influence the mothers' health status, usually debilitating them and reducing the possibility to enter the paid work market. Also, in many low-income countries, cash crop production of fruits, vegetables and flowers involves exposure to toxic chemicals. For example, the adverse health effects of pesticide exposure include poisoning, cancer, skin diseases, abortions, premature births, and malformed babies, happens to female floricultural workers in Kenya and Ethiopia. Furthermore, reproductive problems such as miscarriages, low birth weight and malformations can arise from exposure to pesticides, solvents and organic pollutants, heavy workload, postural factors and shift work. Breast milk can also be contaminated by chemical exposures. Women cooking on open stoves risk burns and exposure to smoke containing toxic pollutants. For instance, in India, there is 
evidence that the use of biomass fuels increases the risk of tuberculosis, particularly in rural areas (Artazcoz et al., 2007; Artazcoz et al., 2009).

As the conceptual frameworks and measures are influenced by the market-driven definition of work as employment, research has concentrated on the relationship between women's paid employment and health rather than women's work and health (Hilfinger Messias et al., 1997: 301). Based on Goode's (1960) theory of scarcity and strain, the stress and overload model reflects the belief that the workplace is a primary stressor and contributor to women's ill health. Nevertheless, this model is more useful to analyse the negative effects of employment on men's health, because women mainly inhabit more distinct occupational spheres than men. Therefore, the relationship between occupation, stress, and health status is not likely to be comparable between women and men.

Household workers are a particularly vulnerable population in terms of health risks. The potential for injury and disease resulting from women's informal caregiving and homemaking work is rarely recognized. In addition, women at home face peculiar forms of violence against them. The Asian dowry deaths are an example; in the last decades in India, Pakistan, and Bangladesh, the number of young women murdered or driven to suicide by continuous harassment and torture by their husbands and in-laws reached high rates.

\section{Gender and Eating Behaviour}

Gender based discrimination in health is reflected in many traditional societies, as women eat after men without joining the table. For instance, in Eritrea it is common for women to save the best food for their male family members. As a result, their nutritional and health statuses are negatively affected by this custom (Fusari, 2011; 96). In a different way, in developed countries, for female teenagers, anorexia (lack of appetite for food, in particular an emotional disorder characterized by an obsessive desire to lose weight by refusing to eat) and bulimia (an emotional disorder characterized by bouts of overeating, typically alternating with fasting or self-induced vomiting or purging) are extreme ways to lose weight influenced by social pressure in order to fit the standards of beauty promoted by media. Thus, the importance of society's view of femininity is the root cause of the increasing incidence of eating disorders. A socialist feminist perspective of eating problems focusses on the commercial motives that companies have in creating and maintaining women's obsession with size and weight; while a radical feminist approach might look at the ways in which women are oppressed by patriarchal standards of appearance. Concepts of appearance 
vary to some extent among ethnic and social class groups. For example, Latinas are defined as feminine when they are not very thin, while white women of the same shape can be considered fat because in the late $19^{\text {th }}$ century, thinness became an element of beauty among middle-class white women (Kramer, 2011; 14).

Female malnutrition is widespread in developing countries due to unequal food distribution within the households, with a tendency towards systematic under-investment in females, as the Body Mass Index (BMI, the most widely accepted measure of adult nutrition) suggests, above all considering its connection with disease, malaria, and poor nutrition. Such issues can be easily related to wellbeing and bearing, and rearing children by malnourished and fatigued mothers, which generates an intergenerational persistence in health problems (Bhalotra \& Rawlings, 2010; 10). As a consequence, the most common intergenerational health effects start with maternal undernutrition and lead to foetal growth retardation, low birth weight, child undernutrition, and ailments in adult children of disadvantaged mothers (Osmania \& Sen, 2003).

\section{Gender and HIV}

The gender inequalities can create, maintain, or exacerbate exposure to risk factors that endanger health. They can also affect the access to and control of resources, including decision making and education, which protect and promote health. Poor women's lack of control over their sexuality and fertility make them vulnerable to HIV/AIDS and other STDs. The interaction between female biology (during sexual relations women are more exposed to the HIV virus) and gender inequalities put women in double jeopardy. For example, at the beginning of the 21st century, infection rates among teenage girls were 5 to 16 times higher than among teenage boys in Sub-Saharan Africa, partly due to easier male-tofemale transmission, and partly by girls' lack of awareness, opportunities, and bargaining power in sexual relations that push them to be the victims of the spread of the disease (Buvinić et al., 2006; 196). In poor countries, the women have shorter survival rates because they come later for treatment or are less likely to seek it; moreover, where there is a high fertility rate, the maternal mortality rate can also reach a high level and affect the survival rates. Disease management strategies have also been less well developed for women (Doyal, 1999).

In low and middle incomes countries, 52 per cent of HIV affected people are women, while it is 48 per cent are men. Nevertheless, in SubSaharan Africa it is 57 per cent of women who are HIV affected. Gender 
inequality not only makes women vulnerable to HIV, but also makes them vulnerable to rape, sex with older men, unequal access to education and economic opportunities (Leclerc, 2008; UNESCO, 2011; ILO, 2012). Furthermore, a married woman can contract HIV because societal standards encourage her husband's promiscuity while simultaneously preventing her from insisting on condom use. The HIV affects the health of women in other ways as well because among the HIV affected women aged 15-24, there are $1.5-2$ times higher chances of tuberculosis (DeLuca, Chaisson, \& Martinson, 2009). Moreover, HIV affected women are more prone to be affected by cervical cancer (Franceschi, 2010). Recent studies of women in Uganda (15-49 years) and South Africa (1526 years) show a positive relation between intimate partner violence and getting affected by HIV, revealing how gender based violence heightens the risk of HIV infection (Jewkes, 2010; Kouyoumdjian, 2013).

\section{Infanticide, Feticide and Maternal Health}

In many South Asian countries, a high mortality rate of girls is registered as they are subjected to aggressive neglect, including foeticide and infanticide. Of course, such practices can be understood only through a comprehensive analysis of gender identities and relations over the course of a lifetime which highlights the gendered hierarchies within the belief systems that prevail there (UN, 2009; 74). According to Raj et al., (2009), in India, the maternal health related complications are due to early marriage and inadequate access to, and control over, use of family planning, contraceptives, and abortion services due to the low status of women and girls in society, which discriminates against them and deprives them of freedom of choice and health facilities. Furthermore, young, rural, and poverty-affected women are most vulnerable. Improved delivery of health services should go along with improved gender relations to achieve enhanced maternal health in the country.

In India, currently, the women have lower healthcare use compared to men, infants, and young children, and perceptible gender disparities exist in fetal, infant, and child mortality (Balarajan et al., 2011). The genderbased violence along with other gender inequities in healthcare affects both maternal and child health. Physical and sexual abuse by husbands affects more than a third of wives in India, marriage at the young age of 8 is prevalent and is correlated with child mortality in girls. Thus mere universal healthcare coverage, without any gender sensitization and empowerment to deal with these issues, will be a failed effort, leaving the 
socio-economically poor and rural women, and adolescent wives and mothers, in great danger.

According to the International Institute for Population Sciences (2007), the National Family Health Survey-3 data (2005-06) in India shows that it is mostly older women, women having children of higher birth orders, Scheduled Tribe women, women with no education, and women in households with a low wealth index who were not receiving antenatal care. Similarly, the poorest, those with no education, Scheduled Tribes, poor women in rural areas and having more than four children were not assisted during their child delivery by a skilled provider, or attendant health facilities during labor and childbirth. Further, 41 per cent of maternal deaths in India are occurring in the age group 15-24, which is the period of highest fertility. Many thousands of young girl between the age of 15-19 die due to pregnancy, abortion or childbirth in spite of 18 years being the legally marriageable age for girls (RGI, 2006). Thus, the deaths due to health related complications are found more with the most vulnerable and marginalized sections of society, including tribal women, Dalit women and poor women from either urban slums or rural areas.

In fact, female infanticide is still practised in societies with strong patriarchal ideologies; at the beginning of the 1990s it was considered the cause of 60 per cent of all infants' deaths in the Chinese Anhui province, accounting for the 12 per cent excess mortality of girls (Buccianti \& Fusari, 2008; Sen, 2003; Vallin, 1993; 196). Moreover, by 1988, in China, sex-determination tests and sex-selective abortion were used to reduce the number of girls born. Uneven access to prenatal care and inadequate treatment of childbirth complications led to high mortality and morbidity rates in women in their childbearing years. In the case of mothers from lower socio-economic status, the infants' health is directly affected.

\section{Female Genital Mutilation}

Female Genital Mutilation (FGM) is a gender-specific health issue as it is the initiation rite that allows a female member to be accepted as a woman in her society, enjoying the rights and duties that such status confers. Many international groups are concerned about FGM, which is practised extensively in parts of Africa and the Middle East and is linked to infections, infertility, and childbirth complications. In fact, the FGM entails a high risk of death due to excessive bleeding (for example, among the Mende of Sierra Leone, blood-letting is an important aspect of the operation) or from tetanus or other infection as a result of the operation. Further, during delivery women can have health problems on account of 
the scar that results from the operation, which makes FGM a grave health hazard to women considering its short and long term consequences (Dolphyne, 1991; 37). According to the estimates of Lightfoot-Klein quoted by Lorber (2000; 53), in Africa in the 1980s there were 94 million women who had their clitorises and vaginal lips cut off. Narrowing the geographical area, in the 1990s the estimates for Egypt are that 80 to 97 per cent of girls have mutilated genitals; while in Sudan and Mali around 90 percent of young girls had these practices done. As this problem also affects migrant communities, in 1996 the United States was the first country to pass a law making all kinds of FGM illegal, and other developed and developing countries started to follow this example.

Although in some countries, such as Eritrea, a law against FGM has been recently declared in order to stop the practice, it will take time to see consistent results as it is a cultural behaviour. Organizations such as the United Nations have campaigned against the practice, calling for its abolition as a matter of global health and human rights. But despite a decades-old movement against it, FGM rates in some countries haven't budged. While younger women are increasingly going unoperated in countries such as Nigeria and the Central African Republic, according to a survey by the Population Reference Bureau (Jacobs \& Clifton, 2010), in Egypt more than 80 per cent of teenagers still undergo the procedure. Studies in anthropology challenge some common misconceptions around FGM, like the belief that it is forced on women by men. In fact, elderly women often do the most to perpetuate the custom. For example, in Kenya, among the nomadic Rendille, girls undergo FGM as part of their wedding ceremony, when they are in their late teens or early twenties. Women were going to a dispensary the day before and they were getting antibiotics and an anti-tetanus injection. They would get a clean disposable razor. Before they had a traditional knife that was used, but they stopped using that, and now every bride has her own clean razor.

In the past, successful indigenous opposition to this activity led to a cultural relativist attitude toward FGM being dominant among governments and international bodies for the first part of 21 st century. This situation has changed over the last 20 years as the women's movement has led an attack on the practice, so that by the mid-1990s all relevant major international bodies and governments without exception had committed themselves to its suppression. Nevertheless, efforts to counter FGM have often been weak and there has been little evidence of their success. The feminist argument about FGM is that it is not only about the control of women but also of their sexuality and sexual pleasure. But talking to people on the ground, the idea that it is a women's business 
emerges. That is to say, it is for women to decide against this practice. The data across Africa shows that the support for the practice is stronger among women than among men. So, the patriarchy argument is not the only one, because FGM is part of demarcating insider and outsider status. This point underlines the importance of women's role in social reproduction, as they can promote changes only when costs exceed immediate benefits. It means that the medical argument to stop these practices is poor because different practices lead to different health outcomes. As a result, the new strategy is legal prohibitions. Now, prohibitions have been put into law in many African countries and 22 countries have specific laws. A couple of countries also have constitutional decrees banning it. The shift from the medical argument to the human-rights argument means that a woman can turn to the state for protection. Therefore, only through appropriate investments in psychological and economic empowerment will women be the most likely group to resist the practice.

\section{Conclusion}

The "feminization of poor health" is not only a consequence of lack of income, but is also the result of the deprivation of capabilities and gender biases present in both societies and its institutions. The social determinants of health are risk factors found in one's living and working conditions, rather than individual factors that influence the risk of disease, or vulnerability to disease and injury.

The above-mentioned instances show that the health-related problems of women are more socio-cultural than biological, as in each of these cases, gender norms and values, and resulting behaviours, are negatively affecting health. Fortunately, gender norms and values are not fixed; they evolve over time and space, and are subject to change, thus promoting the societal change with a view to eliminating gender as a barrier to good health where the entire population can benefit. Hence, there are at least three broad groups of factors able to influence the female approach to health: the first is the service factor, which include accessibility, affordability, and adequacy of the health and social facilities to meet women's needs. The user's factors form the second group, which include social constraints (mobility, incomes, burdens, and so on) leading to asymmetric information about health needs and rights also due to marital status, family roles, work conditions. Finally, the third group is based on men's decision-making power and control over health budgets and facilities at institutional level. Such management affects local perceptions of 
illness and norms concerning treatment, stigmatization and discrimination in health settings, above all among the poor and in minority groups.

As health is a vital driver of economic development, in 2000 the 189 member states of the United Nations the Millennium Development Goals made a commitment in eight goals (Millennium Development Goals: MDGs), aimed at reducing poverty, promoting education, improving maternal and child health, combating HIV/AIDS and other STDs, promoting gender equity. Looking through such goals, it is easy to catch the key role appointed to women, as their health is a fundamental condition for sustainable development, because only improving women's health is possible to improve the health of families, and of the whole population. MDGs are gender-centred because gender can have a major impact on development, so it is necessary to call for an end to genderbased disparities within society.

\section{References}

Alkire, S. (2002). Valuing Freedoms: Sen's Capability Approach and Poverty Reduction. New Delhi: Oxford University Press.

Artazcoz L., Cortès I., Borrell C., Escribà-Agüir V., Cascant L. (2007). 'Gender perspective in the analysis of the relationship between long work hours, health and health-related behaviour.' The Scandinavian Journal of Work, Environment and Health 33: pp. 344-350

Artazcoz L., Cortès I., Escribà V., CascantL.,Villegas R. (2009). 'Understanding the relationship of long working hours with health status and health-related behaviours.' Journal of Epidemiology and Community Health 63(7): pp. 521-527

Balarajan Y, Selvaraj S, Subramanian SV (2011). 'Healthcare and equity in India.' Lancet; published online Jan 12. DOI: 10.1016/S01406736(10)61894-6.

Bhalotra S., S. Rawlings (2010). Intergenerational Persistence in Health in Developing Countries: the Penalty of Gender Inequalities, Discussion Paper n. 5371, Bonn: Institute for the Study of Labor

Buccianti, C., \& Fusari, V. (2008). Lineamenti di Etnodemografia, Padova: Cedam.

Buvinić M, A. Medici, E. Fernández, A.C. Torres (2006). 'Gender Differentials in Health.' In Jamison D.T., J.G. Breman, A.R. Measham et al., Disease Control Priorities in Developing Countries, Washington: World Bank

Cagatay, N. et al (2000). Budgets as if People Mattered: Democratizing Macroeconomic Policies, New York: UNDP. 
Charles, N., \& Kerr, M. (1988). Women, Food and Families. Manchester: Manchester University Press.

DeLuca, A., Chaisson, R., \& Martinson, N. (2009). 'Intensified Case Finding for Tuberculosis in Prevention of Mother-to-Child Transmission Programs: A Simple and Potentially Vital Additional for Maternal and Child Health.' Journal of Acquired Immune Deficiency Syndrome, 50: pp. 196-199.

Dessallien, R. (2005). Review of Poverty Concepts and Indicators, UNDP Publications.

Dolphyne, F.A. (1991). The Emancipation of Women. An African Perspective, Accra: Ghana University Press.

Doyal, L. (1999). Draft Framework for Designing National Health Policies with an Integrated Gender Perspective New York: UNDAW.

Franceschi, S., \& Ronco, G. (2010). 'The Prevention of Cervical Cancer in HIV Infected Women.' AIDS, 24: pp. 2579-2580.

Fusari, V. (2011). Dinamiche Etnodemografiche all'Interno dello Spazio Geopolitico Eritreo.Siena: Libreria Scientifica.

Goode, William J. (1960). 'A theory of strain.' American Sociological Review 25: pp. 483-496

Hartigan, P. (1999). Communicable Disease, Harvard: Harvard Centre for Population and Development Studies.

Hilfinger Messias Deanna K., Im E.O., Page A., Regev H., Spiers J. (1997). 'Defining and redefining work: implications for women's health.' Gender and Society 11(3): pp. 296-323

IBRD (2000). India Country Study on Reducing Poverty, Accelerating Development, New Delhi: Oxford University Press.

ILO (2012). Key Indicators on the Labour Market, Geneva: ILO.

Jacobs, C. F., \& Clifton, D. (2010). 'Female Genital Mutilation/Cutting: Data and Trends Update 2010.' Retrieved June 2013, from Population Reference Bureau: http://www.prb.org/Publications/Datasheets/2010/fgm2010.asp

International Institute for Population Sciences (IIPS) and Macro International (2007). National Family Health Survey (NFHS) 2005-06: India Vol. 1, IIPS Mumbai.

Jewkes, R. (2010). 'Intimate Partner Violence, Relationship Power Inequity, and Incidence of HIV Infection in Young Women in South Africa: A Cohort Study.' The Lancet, 376: pp. 41-48.

Kouyoumdjian, F. (2013). 'Intimate Partner Violence is Associated with Incident HIV Infection in Women in Uganda.' AIDS, 27(8): pp. 13311338 . 
Kramer, L. (2011). The Sociology of Gender, Oxford: Oxford University Press.

Leclerc, M. S. (2008). 'Age-disparate and intergenerational sex in southern Africa : The dynamics of hyper vulnerability.' AIDS, 22(4): pp. 17-25.

Lerner, G. (1986). The Creation of Patriarchy, New York: OUP.

Lorber, J. (2000). 'Women Get Sicker but Men Die Quicker: Gender and Health.' In P. Brown, Perspectives in Medical Sociology (pp. 40-70). Long Grove: Waveland Press.

Moss N.E. (2002). 'Gender equity and socioeconomic inequality: a framework for the patterning of women's health.' Social Science \& Medicine 54: pp. 649-661

Osmania S., Sen A. (2003). 'The Hidden Penalties of Gender Inequality: Fetal Origins of Ill-Health.' Economics and Human Biology 1(1): pp. 91-104.

Payne, S. (1991). Women, Health and Poverty : An Introduction, London: Harvester Wheatsheaf.

Raj, A., Saggurti, N., Balaiah, D., \& Silverman, J. (2009). 'Prevalence of Child Marriage and its Impact on the Fertility and Fertility Control Behaviours of Young Women in India.' Lancet 373: pp. 1883-1889.

Registrar General, India(RGI) and Centre for Global Health Research, University of Toronto. (2006). Maternal Mortality in India: 19972003, Trends, Causes and Risk Factors. New Delhi: Registrar General, India

Rubin, G. (1975). 'The Traffic in Women: Notes on the Political Economy of Sex.' In R. Reiter, Towards an Anthropology of Women (pp. 157209). New York: Monthly Review Press.

Ruger J.P. (2006). 'Ethics and governance of global health inequalities.' Journal of Epidemiology and Community Health 60(11): pp. 998-1003

Santow, G. (1995). 'Social Roles and Physical Health: The Case of Female Disadvantage in Poor Countries.' Social Science and Medicine 40: pp. 147-161.

Schultz, T. P. (1997). 'Inequality in the distribution of personal income in the world: How it is changing and why.' Paper presented at the annual meeting of the Population Association of America, March 27-29, Washington, DC.

Sen, A. (2003). 'Missing Women - Revisited.' British Medical Journal 327: pp. 1297-1298.

Silliman J. (1997). 'Making the connections: women's health and environmental justice.' Race, Gender \& Class 5(1): pp. 104-129 
Townsend, P. (1979). Poverty in the United Kingdom, Harmondsworth: Penguin

True, J. (2012). The Political Economy of Violence Against Women, New York: Oxford University Press.

Turner, Ralph H. (1978). 'The role and the person.' American Journal of Sociology, pp. 84: 1-22

UNESCO (2011). Education Counts: Towards the Millennium Development Goals, Paris: UNESCO.

United Nations (2009). Rethinking Poverty. Report on the World Social Situation, New York: United Nations.

United Nations (2012). Millennium Development Goals Report, New York: United Nations.

Vallin, J. (1993). 'Social Change and Mortality Decline: Women's Advantage Achieved or Regained?' In N. Federici, M. K. Oppenheim, \& S. Sogner, Women's Position and Demographic Change (pp. 120221), Oxford: Clarendon Press.

Vogel, U. (1986). 'Rationalism and Romanticism: Two Strategies for Women's Liberation.' In J. Evans, J. Hills, K. Hunt, E. Meehan, T. T. Tusscher, U. Vogel, et al., Feminism and Political Theory (pp. 17-46), London: Sage Publications.

Wharton, A. (2005). The Sociology of Gender: An Introduction to Theory and Research, USA: Blackwell.

- (1979). 'Some Preliminary Notes on the Subordination of Women.' IDS Bulletin, 10 (3), pp.10-13.

WHO (2009). Women and Health: Today's Evidence, Tomorrow's Agenda, Geneva: World Health Organization

-. (2013). Global and Regional Estimates of Violence Against Women: Prevalence and Health Effects of Intimate Partner Violence and NonPartner Sexual Violence, Italy: WHO

Zinn, M., \& Eitzen, D. (1996). Diversity in Families, New York: Harper Collins College Publishers. 